\title{
Modified Delivery Approach - A New Perspective
}

\author{
Rui Xavier \\ Hospital da Arrábida, Porto \\ Portugal
}

\section{Introduction}

Every rhinoplasty begins with the analysis of the patient. For this analysis it is very important to carefully assess not only the nose, but also the facial features and the morphological characteristics of the patient's body. After this evaluation a list of the surgical techniques necessary to achieve the desired nose is drawn and, according to this surgical planning, the surgical approach is selected.

The surgical approach should provide adequate exposure of the nasal structures that are to be addressed by surgery, and should allow the various surgical techniques to be executed without difficulty and without jeopardizing the nasal structures. For providing adequate exposure, however, every approach has to divide or to elevate nasal cartilaginous and soft tissues structures, and this may interfere, to a certain degree, with the natural mechanisms of tip support and strength. Several nasal structures are unanimously recognised as contributing to the tip support. The factors influencing this support are usually classified as the major and the minor tip support mechanisms. The major tip support mechanisms are: the size, shape, thickness and resilience of the alar cartilages; the upper lateral cartilages attachment to the cephalic margin of the alar cartilages; the attachment of the medial crura footplates to the caudal septum. The minor tip support mechanisms are: the ligamentous sling spanning the domes of the alar cartilages; the membranous septum; the cartilaginous septal dorsum; the nasal spine; the sesamoid complex extending the support of the lateral crura to the piriform aperture; the attachment of the alar cartilages to the overlying skin and musculature. $(3,4)$.

Recent studies have underscored the role of the upper lateral cartilages attachment to the cephalic margin of the alar cartilages to maintain a strong tip support $(5,6)$. It has been demonstrated that this attachment is made of fibrous tissue consisting of dense collagen fibers, all orientated in a single direction, thus fulfilling the criteria of a true ligament (5).

Another study demonstrated that the most efficient way to release the tip as to be freely moved is severing these fibrous attachments between the upper lateral and the alar cartilages (6), thus highlighting the role of this ligament to the tip support. Every effort should be made, therefore, to preserve these collagen fibres during rhinoplasty, in order not to weaken the support of the nasal tip. This should be kept in mind while performing rhinoplasty, as well as while choosing the approach for surgery. 
The three standard approaches for rhinoplasty are the non-delivery approach, the delivery approach and the open approach (7).

The non-delivery or cartilage-splitting approach is very suitable to achieve minor modifications of the nasal tip, such as a moderate increase in tip rotation or an improvement in tip definition $(3,8,9)$ and also provides good access to the upper two thirds of the nose, particularly when reduction techniques to the dorsum are being planned. This approach involves only one incision, a transcartilaginous incision.

The non-delivery approach is particularly suitable for patients with reasonable tip symmetry, normal domal angles and normal or almost normal interdomal distance (3). The great advantage of this approach is its simplicity and easiness to perform, with good and predictable results (8), as it causes almost no interference to the natural mechanisms of tip support $(7,10)$.

The delivery approach is an elegant approach that allows more delicate tip work than the non-delivery approach. Two incisions are usually made for this approach: an intercartilaginous incision and a marginal incision.

This intercartilaginous incision may cause scarring at the valve area, if not made slightly caudally to the caudal border of the upper lateral cartilages (9). It may also promote weakening of one of the major support mechanisms of the nasal tip, the upper lateral cartilage attachment to the cephalic margin of the alar cartilage $(10,11)$.

Nevertheless, besides providing access to the upper two thirds of the nose, the delivery approach is often used to correct bifidity or asymmetry of the tip, to achieve extra tip rotation or to change tip projection $(7,9)$. With the delivery approach, precise excision of cartilage is possible, as well as it is possible to introduce and fixate cartilaginous grafts. It is also possible to interrupt the continuity of the alar cartilages in order to change nasal tip projection and rotation, or to enhance tip projection with a lateral crura steal (9). The delivery approach allows an excellent exposition of the alar cartilages that may, thus, be remodelled as necessary. This approach is particularly useful in patients with a non triangular tip (on basal view), with wide domal angles and large interdomal distance $(3,8)$.

The open approach uses a marginal incision and an external (columelar) incision. The great advantage of this approach is the superb visual control of every structure of the nasal framework that it allows $(7,12,13)$. Another advantage of the open approach is affording an enhanced surgical exposure, facilitating nasal sculpturing by suturing or by the introduction and fixation of different kind of grafts. Any modification of the cartilages can be performed and the result may be easily assessed. The open approach allows maximal exposure of the tip, improving diagnosis and facilitating correction of gross deformities $(11,14,15)$.

The extra time necessary for the approach and for carefully closing the incisions cannot be considered a drawback of the open approach, and the interference that the open approach causes to the mechanisms of tip support $(3,10,13)$, although relevant, may be overcome by using surgical techniques that reinforce this support at some stage of the procedure (10).

The open approach, however, does leave an extensive submucous wound area, leading to a prolonged edema and to longer healing time (3); there may be sensory disturbances at the tip area and there will be an external scar, which may be of concern for some patients and that, eventually, may not be completely undistinguishable. 
Due to its maximal surgical exposure, improved diagnosis and facilitated correction of deformities, the open approach is particularly useful for patients with marked asymmetry of the tip, patients undergoing major reconstruction of the tip or of the upper two thirds of the nose and patients whose complete diagnosis is still unclear after a careful preoperative analysis of the nose $(3,9)$.

The non-delivery approach, the delivery approach and the open approach are the three standard approaches for rhinoplasty. Some surgeons always perform rhinoplasty by using an open approach, others always use an endonasal approach; we believe that every facial plastic surgeon should be familiar with all approaches, as the choice of the approach should not be dictated by the preferences of the surgeon but, mainly, by the nasal deformities of the patient and by the surgical techniques that have been planned in order to achieve an improvement in nasal functioning and aesthetics.

The simplest approach that allows the planned surgical techniques to be performed without difficulty should be selected, to cause the least disturbance to the tip support $(3,7,13)$. The surgeon must always weigh the surgical trauma caused by the approach against the surgical exposure afforded by the approach. In other words, the approach should be as invasive as necessary, but, at the same time, as non invasive as possible.

A frequent goal of rhinoplasty is achieving an improvement in tip definition; for this purpose it is often advisable to resect the cephalic margin of the lateral crura of the alar cartilages, sometimes combining this procedure with other techniques, such as single dome or double dome sutures, or scoring or morselization of the cartilages. The delivery approach is very appropriate to accomplish these manoeuvres, and is widely used $(3,9)$.

If the patient has long alar cartilages (in the cranial-caudal direction), it is particularly important to resect a cephalic piece of the lateral crura to improve tip definition. In this kind of cartilages, however, it may be difficult to deliver the alar cartilages without twisting or tearing the most lateral part of the lateral crura and the intermediate crura or even the dome area. The dome segment is usually the thinnest and most delicate portion of the entire alar cartilage (16) and any weakening of this portion may endanger the resilience of the cartilage, which could compromise the support of the nasal tip. When planning surgery, the open approach may be chosen to overcome this; however, a modified delivery approach may also be used, turning the exposure of the tip cartilages easier and safer, and avoiding using an intercartilaginous incision, which could interfere with the tip support.

\section{Surgical technique}

For the modified delivery approach a transcartilaginous incision is first used in each side of the nose. The position of this incision must take into account that the exact amount of cartilage to be resected may be difficult to assess at this stage, so care must be taken to leave an appropriated sized cartilage caudal to the incision (figure 1). The cephalic piece of the alar cartilage is dissected free in the vestibular and in the non-vestibular sides and resected (figure 2). This procedure is repeated in the opposite side of the nose.

Then a marginal incision is made (figure 3), and the remaining alar cartilage is dissected in the non-vestibular side and easily delivered (figure 4). After the same procedure is 
performed in the opposite side, both alar cartilages are delivered. At this stage of the procedure the size of the remaining alar cartilages is assessed; if necessary, further cephalic resection is done in order to achieve perfect symmetry or to achieve the desired size of the alar cartilages (figure 5).

The rhinoplasty may then proceed with other surgical techniques to the alar cartilages, which may be grafted, sutured or modified as considered necessary to achieve a good functional and aesthetic result (figure 6). After addressing the upper two thirds of the nose, at the end of surgery both the transcartilaginous and marginal incisions are closed with an absorbable suture material.

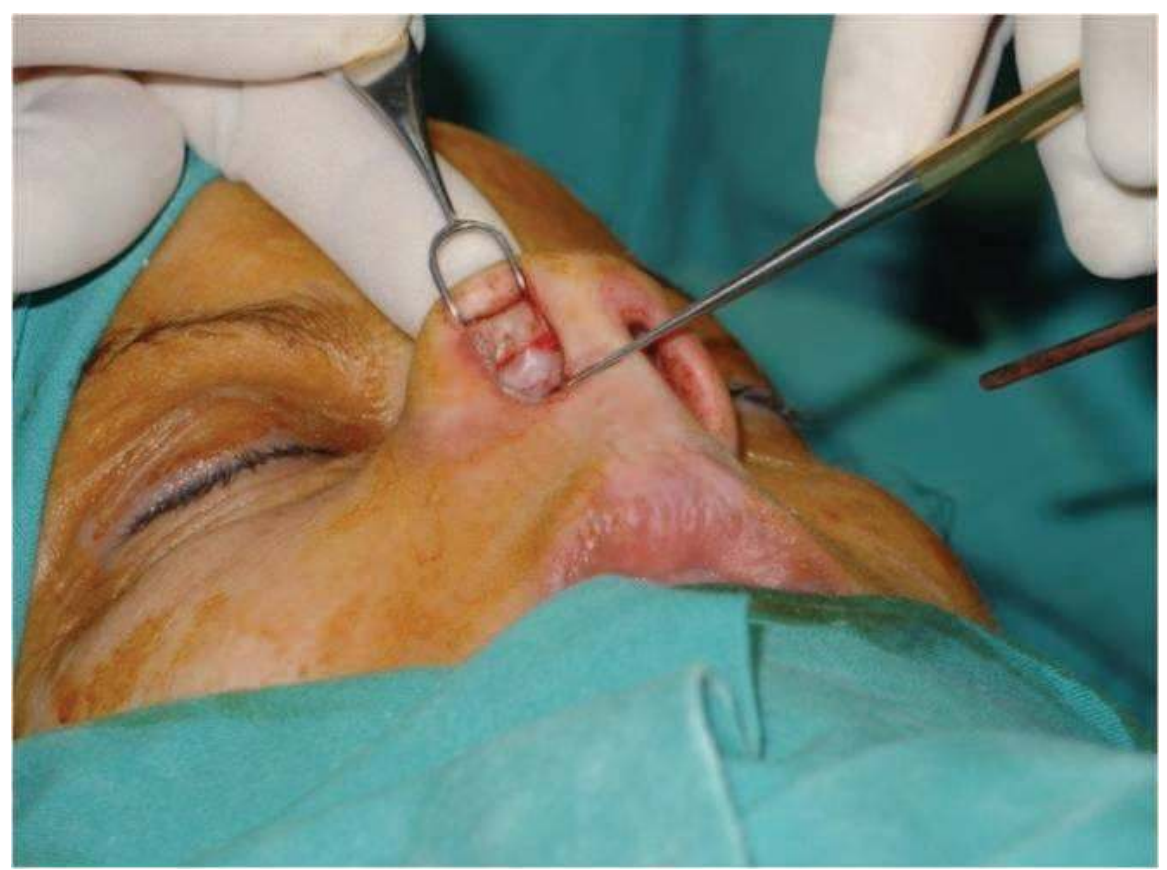

Fig. 1. A transcartilaginous incision is first used, taking care to leave an appropriated sized cartilage caudal to the incision

\section{Comments}

A large proportion of patients seeking rhinoplasty will benefit from surgery of the nasal tip. This may involve major reconstruction for correction of gross asymmetry or deformity of the tip cartilages, usually achieved by using an open approach. For most patients, however, the nose will benefit from performing slight modifications in tip rotation or projection, from correcting a bifid or boxy tip or from improving tip definition. These modifications can be achieved by using an endonasal approach, usually a delivery approach.

Though very appropriate for performing these surgical manoeuvres, the delivery approach has been criticized by some surgeons, and one of the reasons for this criticism is the intercartilaginous incision usually used for this approach. 
If not placed slightly caudal to the caudal border of the upper lateral cartilages, the intercartilaginous incision may lead to scarring of the valve area (9), which could compromise the breathing capacity of the nasal cavity due to narrowing of the internal nasal valve.

We have been using this modified delivery approach for several years without any complications. Several clinical cases of patients operated on by using this approach have previously been reported $(1,2)$.

Another reason for criticizing the intercartilaginous incision is the damage produced by this incision on the collagen fibers situated between the upper lateral cartilages and the cephalic border of the alar cartilages. The importance of the attachment between these cartilages has been well recognized for a long time and considered a major tip support mechanism. Recently, this attachment has been described as a true ligament, due to the fact that it is made of dense collagen fibers organised in a single direction (5).

The advantage of this modified approach over the traditional delivery approach is avoiding the intercartilaginous incisions. The dense collagen tissue between the upper lateral and the alar cartilages will not be severed by using a transcartilaginous incision, thus preventing weakening of the tip support. It has been shown that dividing this fibrous tissue has much more effect on releasing tip structures than dividing any other soft tissue important to the tip support mechanisms (6), emphasising the importance of keeping this tissue to maintain a strong tip support.

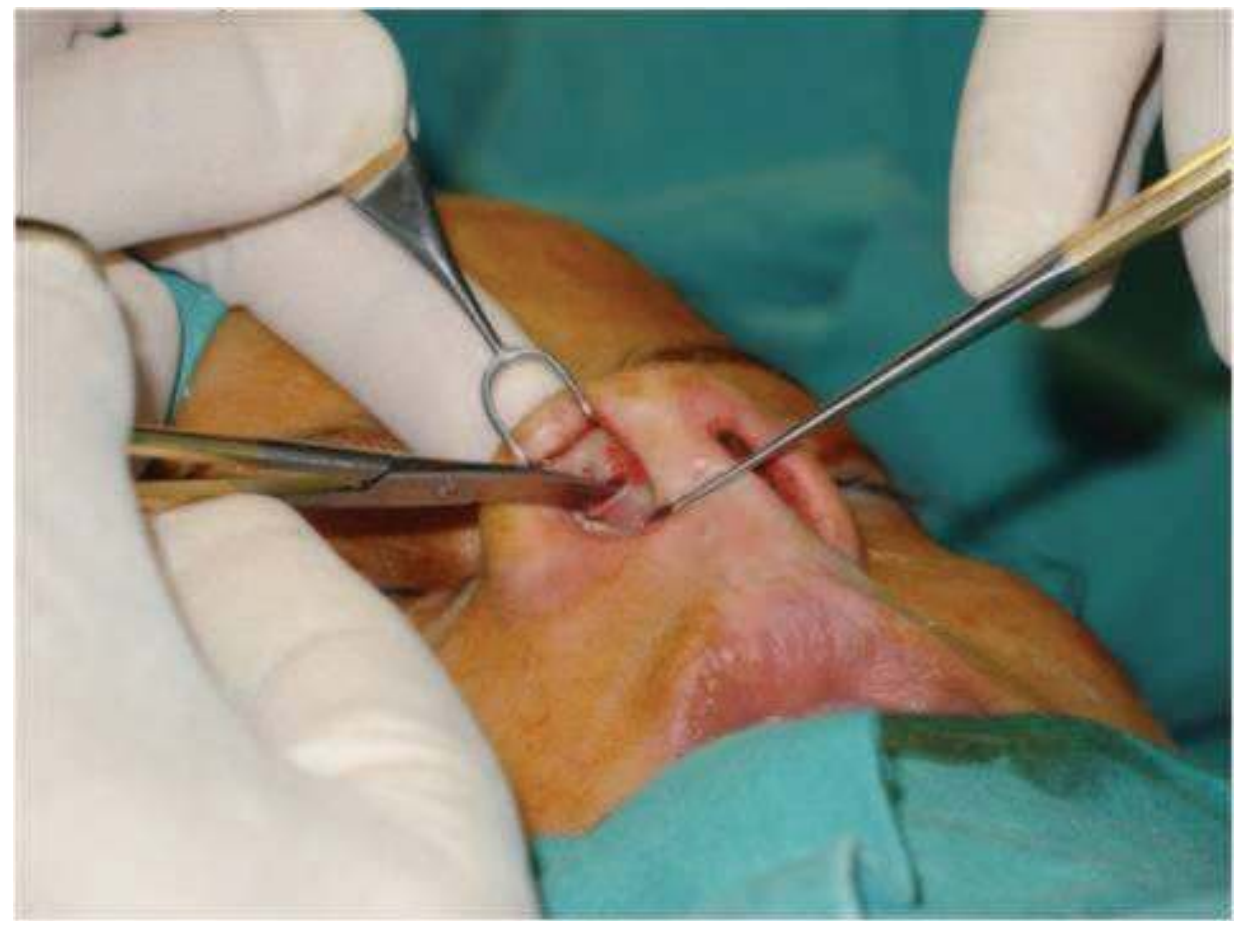

Fig. 2. The cephalic piece of the alar cartilage is dissected and resected 


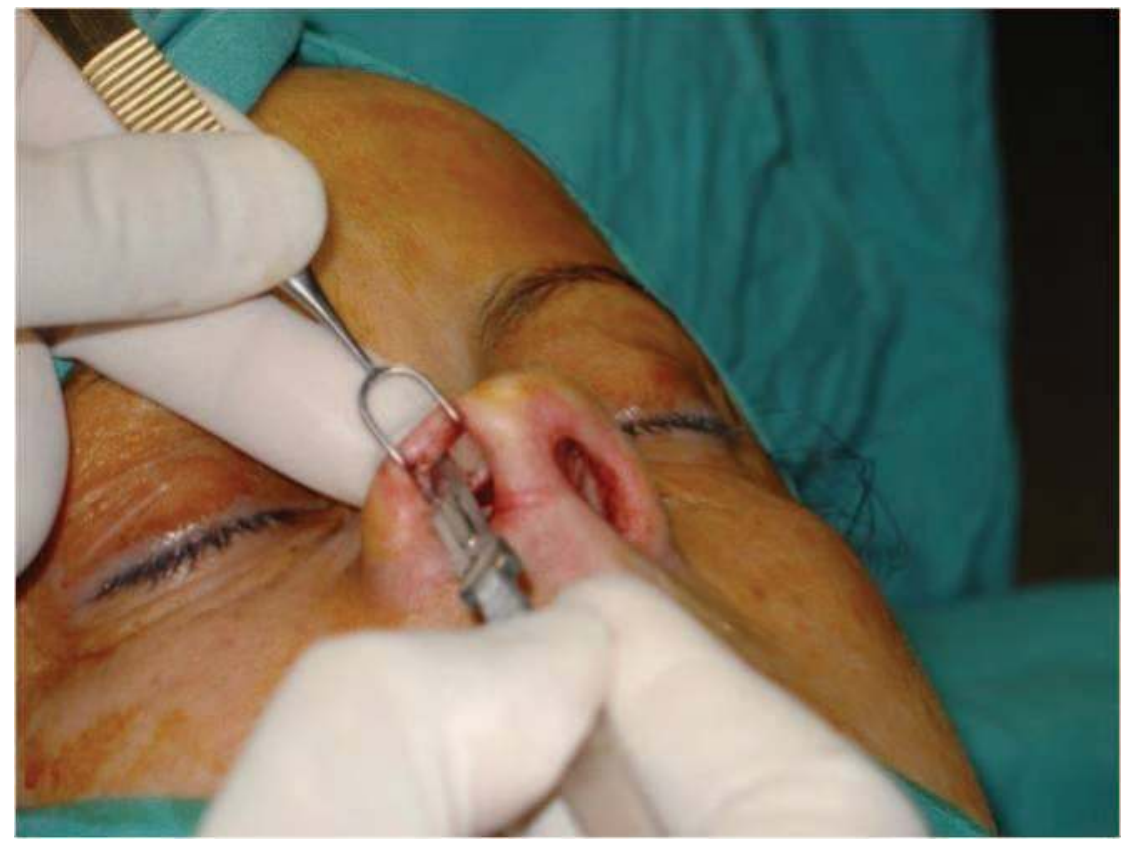

Fig. 3. A marginal incision is made

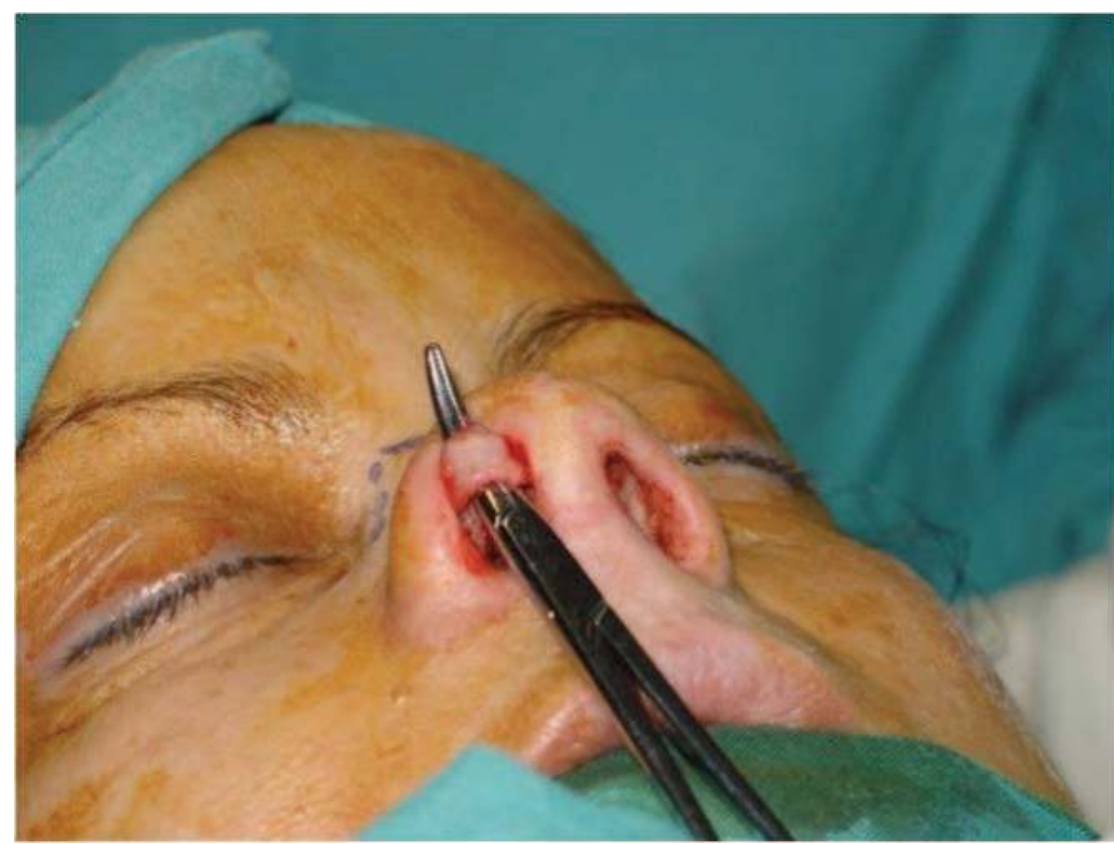

Fig. 4. The remaining alar cartilage is dissected in the non-vestibular side and delivered 


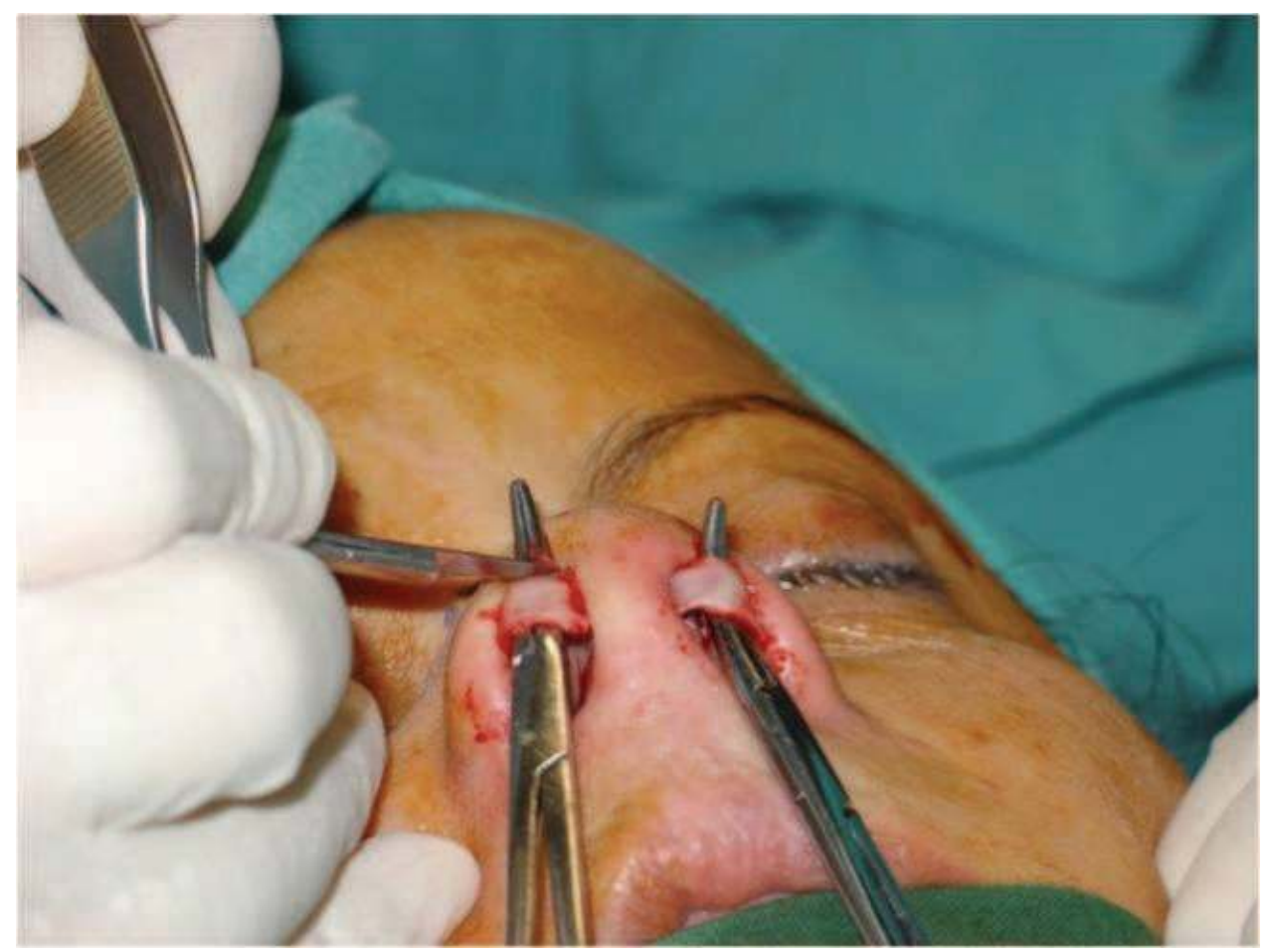

Fig. 5. The remaining alar cartilages are delivered and compared; if necessary, further resection is performed to achieve perfect symmetry or the desired size

We have been using this modification of the delivery approach for several years. In the earlier cases, we used this modified delivery approach only for patients with long alar cartilages (in the cranial-caudal direction) and a wide or bifid nasal tip. We felt that this kind of tip required performing cephalic resection of the alar cartilages plus, if nothing else, a double dome suture. We felt that this modification could make the delivery of long alar cartilages easier and safer, as the cartilage would not be under tension or under a twisting strength at any stage of the procedure. In more recent cases, we have been using this approach for most cases of refinement of the nasal tip, as long as this involved more than just cephalic resection of the alar cartilages. Thus, we have been using the modified delivery approach in almost every case that we would, otherwise, be using the standard delivery approach.

The purpose of this modification is combining the advantages of the non-delivery approach with the advantages of the delivery approach in the same procedure, and avoiding an intercartilaginous incision. Thus, the delivery of each alar cartilage is performed in two stages: at the first stage a cephalic piece of the cartilage is resected; at the second stage the remaining alar cartilage is delivered.

The exact amount of cartilage to be resected may be difficult to assess at the first stage, so it is crucial to leave an appropriated sized cartilage caudal to the transcartilaginous incision. At the second stage, after the delivery of the remaining alar cartilages on both sides, these 
are easily assessed and compared. Further cephalic resection of the alar cartilages may be performed at this stage of the procedure, in order to achieve perfect symmetry or to achieve the desired size of the cartilages.

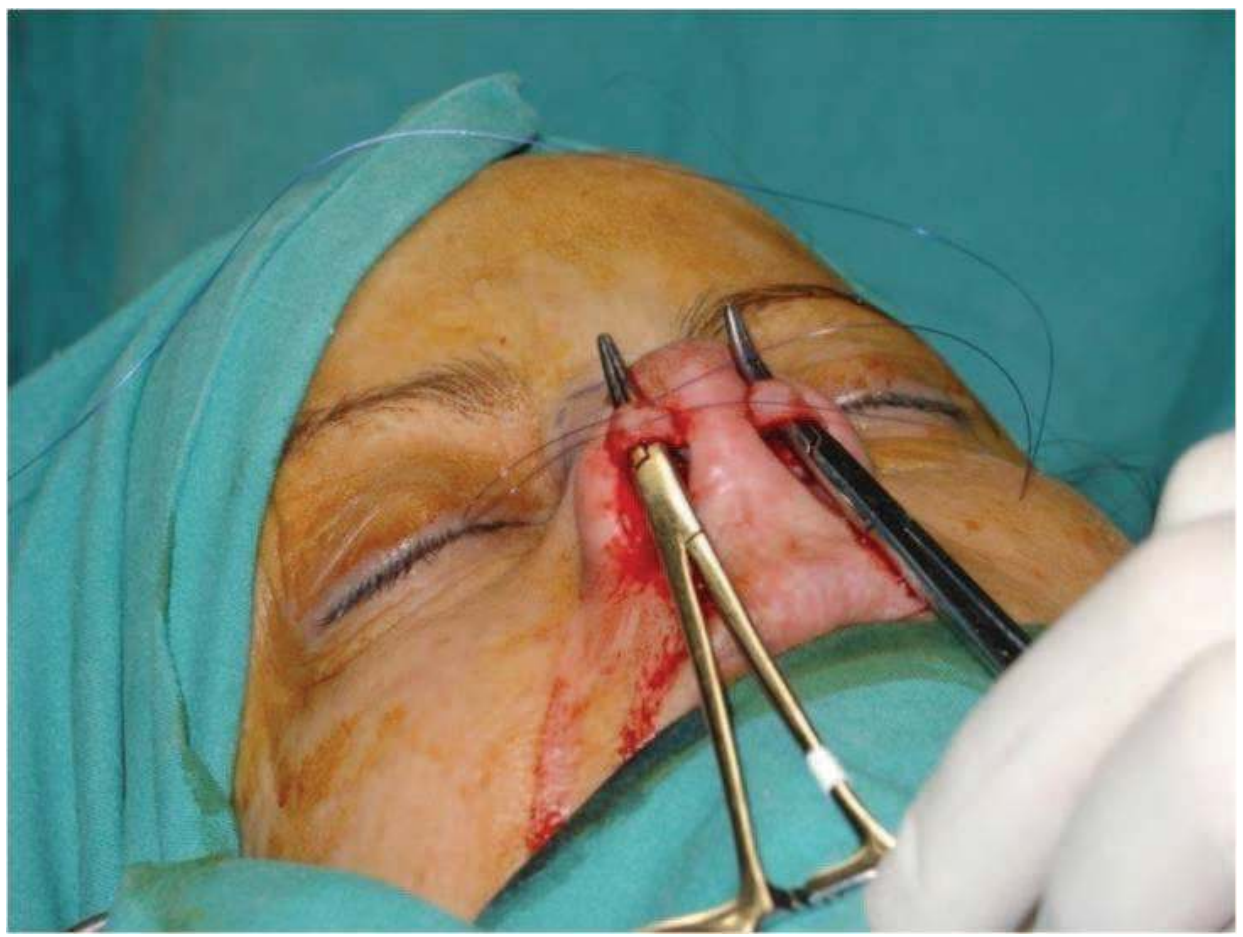

Fig. 6. The other planned manoeuvres, such as domal suturing, are performed

By using first a transcartilaginous incision and then a marginal incision to deliver the alar cartilages, this modified approach combines the reliability of the non-delivery approach with the enhanced exposure of the more powerful delivery approach. By using a transcartilaginous incision instead of an intercartilaginous incision, this modified delivery approach does not promote weakening of one of the major tip support mechanisms, the attachment of the upper lateral cartilages to the cephalic margin of the alar cartilages.

\section{Conclusion}

In rhinoplasty it is often necessary to perform cephalic resection of the alar cartilages to improve tip definition, sometimes combining this procedure with other surgical techniques to the tip, such as single dome or double dome sutures.

The delivery approach may be appropriate to allow all these surgical techniques to be easily executed. However, the intercartilaginous incision usually done for the standard delivery approach may cause a weakening of the tip support by severing the dense collagen fibers at the intercartilaginous region. 
A modified delivery approach may be a way to overcome these dangers, facilitating the exposure of the tip cartilages. This modified approach, using a transcartilaginous and a marginal incision, combines the reliability of the non-delivery approach with the enhanced exposure of the delivery approach and avoids the dangers of the intercartilaginous incision.

We have been using this modified delivery approach for several years, and found it particularly useful for patients with long alar cartilages and a wide or bifid nasal tip. We believe that, in this kind of tip, this modified approach is easier to perform and safer to the tip support mechanisms.

\section{References}

[1] Xavier R. Tip rhinoplasty - a modified delivery approach. Rhinology 2009; 47:132-5.

[2] Xavier Rui. A modified delivery approach. In: Shiffman MA, Di Giuseppe A ed. Advanced Rhinoplasty: Art, Science, and New Clinical Techniques. Berlin: SpringerVerlag, in the press

[3] Tardy ME. Contemporary rhinoplasty: principles and philosophy. In: Behrbohm H, Tardy ME ed. Essentials of Septorhinoplasty. Stuttgart-New York: Thieme, 2004: 3763

[4] Gassner HG, Sherris DA, Friedman O. Rhinology in rhinoplasty. In: Papel ID ed. Facial Plastic and Reconstructive Surgery. Stuttgart-New York: Thieme, 2009: 489506

[5] Han SK, Lee DG, Kim JB, Kim WK. An anatomic study of nasal tip supporting structures. Ann Plastic Surgery 2004; 52:134-9.

[6] Han SK, Ko HW, Lee DY, Kim WK. The effect of releasing tip-supporting structures in short-nose correction. Ann Plastic Surgery 2005; 54:375-8.

[7] Nolst-Trenité GJ. Basic approaches and techniques in nasal tip surgery. In: NolstTrenité GJ ed. Rhinoplasty $3^{\text {rd }}$ Ed. The Hague: Kugler Publications, 2005: 87-96

[8] Tardy ME, Toriumi DM, Hecht DA. Philosophy and principles of rhinoplasty. In: Papel ID ed. Facial Plastic and Reconstructive Surgery. Stuttgart-New York: Thieme, 2009: 507-528

[9] Nolst-Trenité GJ. Surgery of the nasal tip: intranasal approach. In: Papel ID ed. Facial Plastic and Reconstructive Surgery. Stuttgart-New York: Thieme, 2009: 563-576

[10] Kim DW, Toriumi DM. Open structure rhinoplasty. In: Behrbohm H, Tardy ME ed. Essentials of Septorhinoplasty. Stuttgart-New York: Thieme, 2004: 117-135

[11] Adamson PA, Litner JA. Open rhinoplasty. In: Papel ID ed. Facial Plastic and Reconstructive Surgery. Stuttgart-New York: Thieme, 2009: 529-546

[12] Vuyk HD, Zijlker TD. Open-tip rhinoplasty. In: Nolst-Trenité GJ ed. Rhinoplasty $3^{r d}$ Ed. The Hague: Kugler Publications, 2005: 115-123

[13] Nolst-Trenité GJ, Vinayak BC. External rhinoplasty: the benefits and pitfalls. In: Nolst-Trenité GJ ed. Rhinoplasty 3rd Ed. The Hague: Kugler Publications, 2005: 125-141

[14] Whitaker E, Johnson C Jr. The evolution of open structure rhinoplasty. Arch Facial Plastic Surg. 2003; 5: 291-300 
[15] Farrior E. Dramatic refinement of the nasal tip. Otolaryngol Clinics of North America. 1999; 32: 621-636

[16] Oneal R, Beil R Jr, Schlesinger J. Surgical anatomy of the nose. Otolaryngol Clinics of North America. 1999; 32: 145-181 


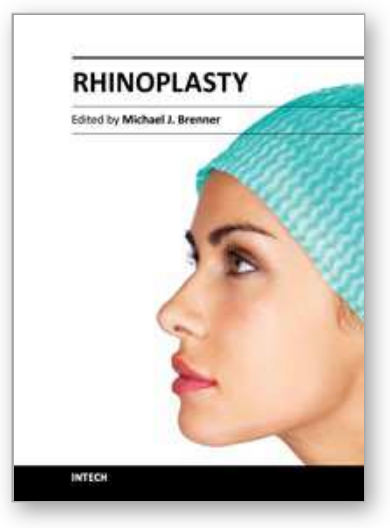

\author{
Rhinoplasty \\ Edited by Dr. Michael Brenner
}

ISBN 978-953-307-849-6

Hard cover, 146 pages

Publisher InTech

Published online 09, December, 2011

Published in print edition December, 2011

Rhinoplasty is one of the defining procedures of plastic and reconstructive surgery. Its roots stem from early efforts in nasal reconstruction to the emergence of modern rhinoplasty. This book describes the latest clinical and research perspectives in rhinoplasty and balances structural correction with aesthetic refinement. With treatises on rhinoplasty from a diverse set of thought leaders from around the world, the collective experience of this books' authors cover cosmetic and reconstructive approaches with a wealth of proven and innovative approaches ranging from minor refinement to major reconstruction. This diversity reflects the inherent complexity of the art and science of rhinoplasty. Discussion of structural approaches is balanced by consideration of judicious resection and refinement. The overarching goal is to instill an understanding of the subtleties of nasal structure and how the natural complexities of nasal anatomy can be adapted to maximize both function and natural appearance.

\title{
How to reference
}

In order to correctly reference this scholarly work, feel free to copy and paste the following:

Rui Xavier (2011). Modified Delivery Approach - A New Perspective, Rhinoplasty, Dr. Michael Brenner (Ed.), ISBN: 978-953-307-849-6, InTech, Available from: http://www.intechopen.com/books/rhinoplasty/modifieddelivery-approach-a-new-perspective

\section{INTECH}

open science | open minds

\author{
InTech Europe \\ University Campus STeP Ri \\ Slavka Krautzeka 83/A \\ 51000 Rijeka, Croatia \\ Phone: +385 (51) 770447 \\ Fax: +385 (51) 686166 \\ www.intechopen.com
}

\author{
InTech China \\ Unit 405, Office Block, Hotel Equatorial Shanghai \\ No.65, Yan An Road (West), Shanghai, 200040, China \\ 中国上海市延安西路65号上海国际贵都大饭店办公楼 405 单元 \\ Phone: +86-21-62489820 \\ Fax: $+86-21-62489821$
}


(C) 2011 The Author(s). Licensee IntechOpen. This is an open access article distributed under the terms of the Creative Commons Attribution 3.0 License, which permits unrestricted use, distribution, and reproduction in any medium, provided the original work is properly cited. 